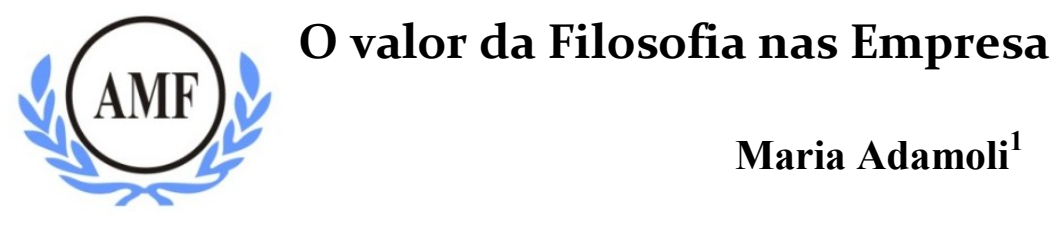

Resumo: Visto que a definição da filosofia institucional é um dos critérios do Modelo de Excelência em Gestão adotado pela Fundação Nacional da Qualidade, e que inúmeras empresas procuram adaptar-se a este modelo, o presente trabalho tem por objetivo analisar os critérios utilizados pelas empresas para identificar seus valores e definir a filosofia empresarial ao estabelecer a Missão, Visão e Princípios e Valores, sendo estes os elementos orientadores e balizadores da Gestão pela Qualidade Total. Ao longo das ultimas décadas tornou-se bastante usual as empresas declararem publicamente sua Filosofia Institucional, enunciando missão, visão, credos, princípios e valores como resultado da implantação de sistemas de qualidade, especialmente com o advento da internet e da criação dos sites oficiais das instituições. No entanto, apesar da grande visibilidade atual, percebe-se que nem sempre a Filosofia Institucional tem sido perfeitamente compreendida em todo seu potencial ideológico. Em inúmeros casos esses elementos estão escritos, mas não comunicam um sentido que alegra, que motiva. É um conjunto de valores que não dão incremento de vida e criatividade às pessoas no trabalho. Este trabalho visa resultar em proposta de pesquisa para o Trabalho Final de Conclusão de Curso e proposta de trabalho futuro com metodologias específicas para a utilização da Filosofia Institucional na facilitação do Desenvolvimento de Equipes, no esclarecimento do sentido do trabalho e na motivação por ações alinhadas aos resultados esperados de cada equipe.

Palavras-chave: Filosofia empresarial; Gestão pela Qualidade Total; MEG-Modelo de excelência em gestão.

\title{
The value of the Company Philosophy
}

\begin{abstract}
Since the institutional philosophy definition is one of the criteria of the Excellence Model of Management adopted by the National Quality Foundation, and numerous companies seeking to adapt to this model, this paper aims to examine the criteria used by companies to identify their values and define the business philosophy to establish the Mission, Vision and Principles and values, which are the guiding elements and a guide for the Total Quality Management. Over the last decades it has become quite usual companies publicly declare its Institutional Philosophy, stating mission, vision, beliefs, principles and values as a result of the implementation of quality systems, especially with the advent of the internet and the creation of official websites of institutions. However, despite the large current visibility, it is clear that not always the Institutional Philosophy has been fully understood in all its ideological potential. In many cases these elements are written, but not communicate a sense that cheers, that motivates. Is a set of values which do not give an increase of life and creative people at work. This work aims to result in research proposal for Work Course Completion Final and proposed future work with specific methodologies for the use of Institutional Philosophy in
\end{abstract}

${ }^{1}$ mariaadamoli@terra.com.br 
facilitating teams Development, to clarify the meaning of work and motivation aligned actions to expected results of each team.

Keywods: Philosophy; Total Quality Management; MEG-model of excellence in management.

\title{
1 Introdução
}

\begin{abstract}
"O homem que vive entre montanhas e vales... sobe ao topo da montanha e, de lá, enxerga longe... muito além... descobre novos horizontes... mas esse mesmo homem, em outro momento, desce aos vales... onde a visão não é tão ampla, nem vai ao longe... mas ele ai é capaz de olhar o que está perto e descobrir os valores de quem com ele convive, experimentando uma relação íntima de amizade... que ditará sua missão de vida" (Dom Bruno Gamberini).
\end{abstract}

Este trabalho de pesquisa tem como tema a Filosofia Institucional e o interesse pelo tema surgiu a partir do estudo de conteúdos das disciplinas de Lógica, Filosofia, Fundamentos Filológicos e Linguísticos, Fundamentos Históricos e Epistemológicos da Ontopsicologia I e Seminários Avançados de Leitura de Textos Filosóficos no Curso de Bacharelado em Ontopsicologia, Primeiro Módulo, realizado e desenvolvido durante o período de março a outubro de 2015, na Faculdade Antonio Meneghetti (AMF).

Surgiu o interesse de investigar sobre este tema por ser um dos requisitos de avaliação da qualidade da gestão das empresas conforme o MEG - Modelo de Excelência em Gestão fundamentado pela filosofia da gestão pela qualidade total e estimulado pela Fundação Nacional da Qualidade em âmbito nacional e pela Associação Qualidade RS - PGQP no Rio Grande do Sul. Este modelo propõe que a empresa desenvolva uma prática de gestão para definir os elementos da filosofia (visão, missão, princípios e valores) necessários à promoção da cultura da excelência, à criação de valor para todas as partes interessadas e ao desenvolvimento sustentável.

O ponto de investigação deste estudo é, principalmente, quanto aos critérios e métodos de definição da Filosofia Empresarial, como contribui para o desenvolvimento das equipes e como é vivida ao interno da empresa. Portanto, é investigar qual é a base elementar concreta sobre a qual as empresas definem a filosofia que se constituirá na base dos pensamentos, decisões e comportamentos organizacionais, como esta filosofia é comunicada às pessoas da força de trabalho, como se torna válida para todos, isto é, como, contribui para fazer a evolução em infinitos percursos da mente no meio empresarial. $\mathrm{Ou}$, talvez, este estudo possa confirmar a hipótese de inexistência destes critérios e métodos tornando estes elementos nulos para contribuições ao desenvolvimento das pessoas. 
Antonio Meneghetti (2013) diz "aqui entra em jogo a Ontopsicologia. Ela fornece critérios que, unidos à metódica corrente, garante uma serena racionalidade de administração" (p. 326). Salienta ainda que "deve-se, porém, pressupor que exista um conhecimento elementar, antes de fazer crítica ou filosofia, ou seja, uma base para fazer o conhecimento para ter capacidade de juízo" (ibid.).

A realidade no mundo dos negócios são mudanças, incertezas, urgência, competição e pressão por resultados. Neste contexto, falar de filosofia empresarial pode ser entendido como algo abstrato, pouco prático e para o qual não há tempo. A grande parte da falta de tempo e dos fracassos nas empresas vem da falha em responder questões básicas sobre a organização, como por exemplo: quem somos, onde estamos, o que iremos fazer, como faremos, por quê. Ao se buscar a aplicação prática desses conceitos junto às empresas, evidencia-se uma lacuna entre o conhecimento, aplicação e contribuição destes para o desenvolvimento e alinhamento das equipes nas empresas.

Dessa forma, o problema de pesquisa foi assim delineado: "Qual é a percepção da empresa a respeito da importância da Filosofia Institucional para o alinhamento e desenvolvimento das equipes?".

O objetivo geral da pesquisa, a partir da problematização, pode ser apresentado do seguinte modo: "Investigar qual é a percepção da empresa a respeito da importância da Filosofia Institucional para o alinhamento e desenvolvimento das equipes”. E os objetivos específicos construídos na pesquisa são:

a) Realizar uma revisão bibliográfica os conceitos fundamentais de Filosofia Institucional;

b) Relacionar estes conceitos com os conteúdos estudados e contextualizar nas empresas;

c) Verificar a possibilidade de estabelecer relações entre a Filosofia Institucional com o Desenvolvimento de Equipes nas empresas.

Este artigo está estruturado em introdução, revisão de literatura, metodologia e conclusão.

\section{Revisão de Literatura}

Filosofia é o uso do saber em proveito do homem. Com esta definição contida no Eutidemo, Platão observa que de nada serviria possuir a capacidade de transformar 
pedras em ouro a quem não soubesse utilizar o ouro, de nada serviria uma ciência que tornasse imortal a quem não soubesse utilizar a imortalidade, e assim por diante. É necessária, portanto, uma ciência em que coincidam fazer e saber utilizar o que é feito, e esta ciência é a Filosofia (ABBAGNANO, 2000).

Segundo este conceito, a Filosofia implica posse ou aquisição de um conhecimento que seja, ao mesmo tempo, o mais válido e o mais amplo possível e uso desse conhecimento em benefício do homem. Esses dois elementos recorrem frequentemente nas definições de Filosofia em épocas diversas e sob diferentes pontos de vista. São reconhecíveis, por exemplo na definição de Descartes, segundo a qual esta palavra significa o estudo da sabedoria, e por sabedoria se entende um perfeito conhecimento de todas as coisas que o homem pode conhecer, tanto para a conduta da sua vida quanto para a conservação de sua saúde e a invenção de todas as artes (ibid.).

O quadro seguinte apresenta definições de filosofia segundo diversos filósofos estudados.

\begin{tabular}{|c|l|}
\hline Aristóteles & Filosofia é a ciência da verdade. \\
\hline Platão & Filosofia é o uso do saber em proveito do homem. \\
\hline Descartes & $\begin{array}{l}\text { Esta palavra significa o estudo da sabedoria, e por sabedoria se entende um perfeito } \\
\text { conhecimento de todas as coisas que o homem pode conhecer, tanto para a conduta da } \\
\text { sua vida quanto para a conservação de sua saúde e a invenção de todas as artes. A } \\
\text { filosofia compreende tudo aquilo que o espírito humano pode saber. }\end{array}$ \\
\hline Hobbes & $\begin{array}{l}\text { A Filosofia é, por um lado, o conhecimento causal e, por outro, a utilização deste } \\
\text { conhecimento em benefício do homem. A Filosofia é o conhecimento adquirido através } \\
\text { do raciocínio correto, dos efeitos ou fenômenos, a partir de suas causas ou origens, ou, } \\
\text { reciprocamente, o conhecimento adquirido sobre as origens possíveis a partir dos efeitos } \\
\text { conhecidos. }\end{array}$ \\
\hline Kant & $\begin{array}{l}\text { Ciência da relação do conhecimento à finalidade essencial da razão humana. Expressava } \\
\text { o campo da Filosofia com as seguintes pergunta: O que posso saber? O que devo fazer? } \\
\text { O que posso esperar? O que é o homem? }\end{array}$ \\
\hline Johann Fichte & Eiência universal e mãe de todas as outras ciências. Filosofia primeira. \\
\hline $\begin{array}{c}\text { Friedrich W. } \text { W ciência da ciência em geral (não deixa qualquer autonomia às ciências particulares). } \\
\text { Schelling }\end{array}$ & $\begin{array}{l}\text { A tarefa da filosofia é aclarar a concordância entre objetivo e subjetivo, ou seja entre } \\
\text { natureza e espírito. }\end{array}$ \\
\hline Hegel & A consideração pensante dos objetos. \\
\hline $\begin{array}{c}\text { Giovanni } \\
\text { Gentile }\end{array}$ & Teoria geral do espírito. A consciência que o eu absoluto tem de si mesmo. \\
\hline Voltaire & Filósofo, amante da sabedoria, da verdade. \\
\hline
\end{tabular}




\begin{tabular}{|c|l|}
\hline Comte & $\begin{array}{l}\text { Ao lado das ciências particulares, deve haver um "estudo das generalidades científicas", } \\
\text { que para ele corresponde a Filosofia primeira de Bacon. }\end{array}$ \\
\hline Wundt & $\begin{array}{l}\text { É a ciência generalizadora e unificadora dos resultados das outras ciências. A } \\
\text { generalização e a unificação devem corresponder a uma imagem do mundo que satisfaça } \\
\text { às necessidades do coração. A função da filosofia é a síntese dos conhecimentos } \\
\text { específicos em uma intuição do mundo e da vida que satisfaça as exigências do intelecto } \\
\text { e as necessidades do coração. }\end{array}$ \\
\hline Locke & $\begin{array}{l}\text { Sua tarefa é verificar a validade do saber, determinando seus limites e condições, suas } \\
\text { possibilidades efetivas. (Divide a Filosofia em três; Filosofia natural, filosofia prática, e } \\
\text { lógica). Filosofia prática ou ética, que é a arte de bem dirigir nossos poderes e nossos } \\
\text { atos para a consecução das coisas boas e úteis. }\end{array}$ \\
\hline Hume & $\begin{array}{l}\text { Tarefa da filosofia identificada com a limitação de nossas investigações às matérias que } \\
\text { mais se adaptam à limitada capacidade da inteligência humana. }\end{array}$ \\
\hline
\end{tabular}

Fonte: elaborado pela autora a partir de estudos em Abbagnano (2000).

Em relação à Filosofia Empresarial, temos que considerar que desde 1993, a Filosofia é uma disciplina recomendada nos cursos de Administração em todo o Brasil. Porém, infelizmente, são muitas as dificuldades de encontrar material didático disponível, em que o ensino da Filosofia seja voltado para o uso do administrador de empresas.

A Filosofia é um dos braços da Administração, é uma ciência interdisciplinar à Administração, e, também, o que mais contribui para o aprendizado dos métodos e conceitos utilizados para atingir as metas e objetivos da organização.

O pensamento filosófico e a atividade de gerenciar negócios, aparentemente, parecem incompatíveis, disciplinas estranhas, cujo entrelaçamento não oferece nada de útil. Em decorrência do estereótipo criado que somente disciplinas consideradas objetivas como Matemática e Contabilidade são essenciais para gerir empreendimentos, frequentemente, os profissionais do meio empresarial concebem o conteúdo filosófico como 'enrolação', 'perfumaria', 'coisa sem praticidade', 'coisa de louco'.

A Filosofia originalmente era a ciência mãe, matriz da qual surgiram as demais ciências e é preciso ter em mente que, desde o surgimento dos questionamentos dos primeiros que filosofaram, o intuito estava em entender as coisas que nos rodeiam, pois, desde os ensinamentos de Sócrates, no século IV AC, uma das máximas do pensamento filosófico adverte que nada do que é humano pode ser estranho ao exercício da reflexão. Nada do que é humano pode ser estranho à Filosofia. Partindo-se da premissa que nada do que é humano possa ser estranho à discussão filosófica, no século IV. a.C, Xenofonte, no Livro IV, Capítulo VII dos Memoráveis, nos fornece instrutivos exemplos dessa concepção ao relatar alguns dos ensinamentos de Sócrates. 
Ensinava-lhes também até que ponto deve o homem versar-se em cada ciência (ABBAGNANO, 2000).

Assim dizia dever aprender a Geometria, o necessário em caso de precisão, medir-se exatamente um terreno que se queira comprar vender, dirigir ou lavrar. O que é tão fácil - acrescentava - que por pouco que se dedique à agrimensura pode se conhecer a grandeza da terra e a maneira de medi-la. Recomendava aprender-se de Astronomia o bastante para viajando-se por terra, por mar ou, estando-se de guarda, reconhecer as divisões da noite, mês e ano e ter pontos de referência para tudo o que faça na noite, mês ou ano. Acrescentava ser fácil aprender esses pontos com os caçadores noturnos, pilotos e todos aqueles que tem interesse em sabê-los (ibid.).

Parafraseando os ensinamentos de Sócrates, poderíamos acrescentar que, contemporaneamente, é preciso analisar a inteligência, a astúcia e coragem dos empreendedores contemporâneos presentes nas mais diferentes teorias da Administração, como propôs na primeira metade do século $\mathrm{XX}$, o pensador e educador norte americano John Dewey, ao enfatizar quão bom seria se a filosofia estivesse voltada mais para os engenheiros e advogados do que simplesmente se voltar única e exclusivamente para a formação de padres (ibid.).

O livro Visão Filosófica das Estratégias em Administração, de Bazanini (2007), concebe que, em nossa contemporaneidade, a filosofia se encontra presente em todos os campos de atividade e a dimensão humana do produzir se constitui em importante aspecto da realização do indivíduo em sua existência cotidiana.

Bazanini (2007) diz que a sociedade contemporânea produziu administradores que são novos e bons filósofos, grandes pensadores do pensamento administrativo enunciaram concepções de mundo assentadas em determinada forma de conduta embora não sejam denominados filósofos.

Frederick Wislom Taylor (1856-1917), norte-americano, inspirador da Administração Científica, um pensador obstinado pelo trabalho eficiência e produtividade, criticou o laissez-faire do empirismo tradicional presentes nas empresas de então; superados na robotização das pessoas, desumanização mas ainda não superado na decisiva melhoria da capacidade de produção enquanto intenção para o incremento exponencial da produção humana (BAZANINI, 2007).

Henry Fayol (1841-1925), francês, elaborou princípios básicos da Administração e a departamentalização com base nos organismos biológicos, e a identificação das 
principais funções da Administração que são, planejar, organizar, controlar, coordenar e comandar (POCCC) (BAZANINI, 2007).

Mary Parker Follet (1868-1933), norte-americana, formou-se em Filosofia, Direito, Economia e Administração pública e foi autora de três livros. Concebeu que somente a identificação com os impulsos sociais subjacentes pode fazer com que os executivos construam grandes organizações. Foi uma autora norteamericana que tratou de diversos temas relativos à Administração, na chamada Escola das Relações Humanas ficando conhecida como a "profetisa do gerenciamento". Suas ideias foram muito revolucionárias para sua época, e, em boa parte, continuam sendo até hoje desafiantes. Ela foi capaz de enxergar através do Homo economicus, dos pensadores do Taylorismo, e propor que o ser humano somente se desenvolve quando carregado de responsabilidade. Com suas teorias, Follett deu maior importância às relações individuais dos trabalhadores e analisou seus padrões de comportamento (ibid.).

Elton Mayo (1880-1949), australiano, psicólogo, sociólogo e pesquisador das organizações, inspirador da Escola das Relações Humanas, enfatizou a importância da motivação na busca da excelência empresarial. O conflito é uma chaga social, a cooperação é o bem-estar social. Conclui-se que: comprovada a existência de uma organização informal, a Experiência de Hawthorne contrapõe o comportamento social do empregado ao comportamento do tipo máquina, proposto pela Teoria Clássica, abrindo assim portas para um novo campo de abordagem da administração: as Relações Humanas (ibid.).

Chester I. Barnard (1886-1961), norte-americano, foi um pensador da Escola das Relações Humanas, corrente da Administração, surgida com a Crise de 1929. Barnard também é tido como um pensador do Behaviorismo. Foi o criador da teoria da cooperação, em que estuda a autoridade e a liderança. Foi um dos primeiros teóricos da administração a ver o homem como um ser social, e a estudar suas organizações informais dentro das empresas. Para ele, as organizações eram sistemas sociais que exigiam cooperação (ibid.).

William Edwards Deming (1900-1993), estatístico norte-americano que procurou unir em um único sistema as visões das Ciências Exatas e das Ciências Humanas. Formulou e divulgou os princípios da Gestão da Qualidade, que contribuíram para a recuperação econômica do Japão e agora estão se tornando um novo paradigma para a administração no ocidente. Deming é amplamente reconhecido pela melhoria dos 
processos produtivos nos Estados Unidos durante a Segunda Guerra Mundial, sendo, porém, mais conhecido pelo seu trabalho no Japão. Lá, a partir de 1950, ele ensinou altos executivos como melhorar projeto, qualidade de produto, teste e vendas (este último por meio dos mercados globais) através de vários métodos, incluindo a aplicação de métodos estatísticos como a análise de variantes e teste de hipóteses (ibid.).

Ainda conforme apresentado por Bazanini (2007), com base nesses dados, o que causa estranheza é o não reconhecimento desses e tantos outros teóricos do pensamento administrativo na condição de filósofos. Entretanto, o mesmo não ocorre com SaintSimon, Fourier, Owen ou socialistas científicos como Marx, Engels, Gramsci, Althusser, Luckacs e outros são considerados dentro da história da filosofia, filósofos de primeira linha.

Os filósofos do capitalismo como Taylor, Fayol, Barnard, Mayo, Follet, Deming, Drucker, Gates e outros, paradoxal e erroneamente desprezados pelos acadêmicos, uma vez que contribuíram decisivamente, cada um ao seu modo, para superação do falso conhecimento, incorporam-se legitimamente ao universo da Filosofia da Administração.

$\mathrm{Na}$ contemporaneidade, depois de termos observado o lado negativo do progresso tecnológico em duas grandes guerras mundiais e na proliferação de armamentos nucleares, as pessoas estão entendendo que, para viver bem se torna cada vez mais necessárias concepções de mundo adequadas à realidade circundante. Além disso, a emergência da nova competição econômica em escala mundial está obrigando as organizações a buscarem a compreensão dos fundamentos de seus negócios, dos mecanismos de cooperação, competição e produção, conduzem à um interesse renovado pela crítica filosófica ao pensamento dos empreendedores da história da administração, cuja contribuição para o desenvolvimento humano se torna inegável. Assim, o livro Visão Filosófica da Administração, de Bazanini (2007), esclarece que a inclusão da filosofia como disciplina básica e instrumental nos currículos dos cursos de Administração se torna não apenas pertinente, mas sim, imprescindível para os futuros executivos. Afinal, nada do que é humano pode ser estranho à Filosofia.

\section{Considerações Finais}

A Filosofia é elaborada a partir da pessoa do líder. Então, seria necessário que preliminar à ação empresarial, antes, o empresário devesse possui um grande 
conhecimento acerca de si mesmo, e também realizar um processo de consultoria de autenticação para conhecer sua identidade e verificar a identidade da ação. É fundamental, também, ao empresário, saber o sentido do trabalho, o sentido do negócio e expressar a filosofia empresarial em todos os elementos: definição do negócio, missão, visão, princípio e valores.

\section{Referências}

ABBAGNANO, Nicola. Dicionário de Filosofia. São Paulo: Martins Fontes, 2000.

BAZANINI, Roberto. Visão filosófica das estratégias em Administração: há controvérsias e conveniências. São Paulo: Plêiade, 2007.

MENEGHETTI, Antonio. Psicologia Empresarial. São Paulo: FOIL, 2013.

MENEGHETTI, Antonio. Fundamentos de Filosofia. São Paulo: Ontopsicológica Editora Universitária, 2005. 